\title{
NAMING COUNTERMEASURES OF ADMINISTRATIVE DIVISION IN SIGHT OF CHINESE NAMING VIEW
}

\author{
R.C. Niu \\ Chinese Academy of Surveying and Mapping, Beijing 100830, P.R.China - niuruch@casm.ac.cn
}

Commission VII, WG VII/6

KEY WORDS: place name, Chinese, administrative division name, naming principle, naming countermeasure

\begin{abstract}
:
Although some progresses have been made after nearly 30 years of research and practice of administrative division renaming in China, there are still many problems which have not been really resolved. Moreover, with the beginning of the second place name census across China, scientific and standard administrative division naming countermeasures are of even more importance. In this paper, the problems in present administrative division naming were analyzed, and the basic characters and principles of traditional Chinese noun naming as well as five taboos in Chinese place naming were described by analyzing the theory of Chinese naming concept. Based on the characters above, principles of administrative division renaming and naming conceptions of administrative division were further discussed and analyzed.
\end{abstract}

\section{INTRODUCTION}

The scientificity and rationality of administrative division naming reflects the level of administration and technological development of a country. The unity of address and writing is related to national sovereignty, national defence construction, national solidarity and economic development. During a period of time, there were defects in the current administrative division naming. To solve this problem, the most fundamental way is to build the scientific system of China's administrative division naming as quickly as possible, making it scientific, serial and standard.

Since the late 1980s, a wide range of research on administrative division naming was carried out in China. Although a lot of results were achieved, many problems still have not been really resolved.

China has launched the second national geographical name census recently. In order to better improve the quality of census results and standardize administrative division names, systematic research needs to be carried out to speed the progress of scientificity, serialization and standardization of China's administrative division naming.

\section{EXISTING PROBLEMS}

Currently, following problems exist in administrative division naming:

(1) Ambiguity and meaning change of City

(2) Ambiguity of District

(3) Chaos of administrative division names at County level

(4) Number of administrative division units at provincial level and local level is high

(5) Meaning change of Town

(6) Proprietary name of counties at provincial level and city level is same

(7) Overlap of administrative division names after County upgrades to City

(8) Administrative division name of place of residence of minorities is not unified
(9) Generic names of city divisions turn into proper names

\section{CHINESE NAMING VIEW}

Since ancient times, naming is an important issue concerned by philosophers and linguists. On Chinese naming view, there had a lively discussion between name and entity in China's Spring and Autumn Period. The relationship between name and entity, is the relationship between concept and things. Huishi, Gongsun Long, and Mo-tse believe that concept should be a true reflection of objective things. In addition, Confucius, Zhuangzi and Xunzi also put forward their own views and elaborations.

\subsection{Basic Features of Chinese Naming}

China's administrative division naming must conform to the characteristics of Chinese language and Chinese naming disciplines. Then, it will be recognized by society, living a long life, and avoiding ambiguity. There are three elements in Chinese place naming, which are linguistic element, social (market) element and legal element. In the naming of proper names, language plays a key role because Chinese naming strictly follows rules of Chinese language. Chinese language has the following main characteristics, which directly affect the brand naming.

In modern Chinese, the main way of word formation is synthesis, which is to combine two or more words together. In the definition of linguistics, word is the smallest unit that can be freely used in the language, and morpheme is the smallest unit which has semantics. The difference between these two is that word can appear in a sentence freely, while morpheme is not sure. Chinese has 3,500commonly used morphemes.

Most morphemes of modern Chinese cannot be used independently. So in order to become a word, it must be synthesized. Another feature of morpheme is monosyllabic, namely a morpheme is a syllable. A Chinese character represents a morpheme or a syllable, and a compound word of two morphemes is two characters. From this we can draw three distinct features of Chinese naming: 
(1) Most of the names are meaningful because the named morpheme itself is meaningful. When people choose a word to name, they must carefully consider the various meanings of the word.

(2) Chinese naming is restricted by following factors: (1) scope of the general election is limited to 3,500 commonly used morphemes; (2) name must conform to rules of word-building; (3) in place naming, most structure is prejudiced structure.

(3) Tone is an important feature which influences Chinese naming. Chinese is a tonal language, and Mandarin has four different tones: first tone, second tone, third tone and the fourth tone. Among them, the first tone and the second tone are hightone, and third tone and the fourth tone are seen as low-tone. In the study of Chinese human naming, it was found that hightones are strongly preferred, and people who speak Mandarin prefer to use morphemes of first tone and second tone. Studies done by scholars on the name of the Hong Kong people have come to similar conclusions.

\subsection{Basic Principles of Chinese Place Naming}

There are four basic principles of Chinese place naming, which are:

(1) Most Chinese names are two-syllable synthesis words

(2) Second syllable of the synthesis name is mostly high-tone

(3) Naming follows prejudiced structure "modifier + Noun"

(4) Naming pursues both good pronunciation and meaning

\subsection{Five Taboos in Chinese Place Naming}

There are five taboos in Chinese place naming, which are:

(1) The use of unfamiliar words is restricted

(2) The use of duplication words is restricted

(3) The use of polyphone is restricted

(4) The use of inauspicious meaning words is restricted

(5) The use of poor homophonic words is restricted

\section{PRINCIPLES OF ADMINISTRATIVE DIVISION RENAMING}

According to above mentioned Chinese naming view and concept and rules of Chinese naming, the principles of Chinese administrative division are given as follows:

(1) Go through the existing names thoroughly and strengthen the research on relationships among names of administrative divisions. Be aware of the etymology, meaning and evolution of existing administrative division names, in order to provide scientific basis for formulating the renaming schemes.

(2) Formulate the renaming scheme. It should be noted that: (1) Try to keep the administrative division names unchanged or change the names as less as possible. (2)For the one that can be unchanged, keep it intact. For example, people are familiar with Jilin Province and Jilin City. In order to void the unnecessary chaos, keep the two names unchanged. (3) For the one that is not sure, keep it unchanged.(4) For the one that needs to be changed, change it while complying with existing laws.

(3) For the one which is more important or easier, implement the renaming scheme first. Firstly, we must take advantages of opportunities to widely publicize the necessity and feasibility of renaming to ensure its smooth progress. Secondly, for the one that must be changed, make great efforts to complete the renaming as quickly as possible in order to avoid protracting. Thirdly, for the one which is more difficult and involves more things, we should handle it in no rush.

(4) Eliminate the phenomena of homonyms of administrative district names at county level gradually. Put the pronunciation, meaning, and origin of names as part of the change report. On the other hand, prevent the emergence of new duplication and homonyms.

(5) Generic names of administrative divisions should be clear, not to have more than one meaning.

(6) Generic names of administrative divisions should be very concise, generally should be one word.

(7) A scientific system of generic names should be established in accordance with current administrative divisions.

\section{NAMING CONCEPTIONS OF ADMINISTRATIVE DIVISION}

\subsection{Proper Names}

The phenomenon that administrative divisions which has homonyms proper names also use the same generic administrative division names should be get rid of in the near future.

If the administrative division has not changed, but two level administrative divisions have the same proper names, one of the proper names should be changed.

City usually has not big areas. The duplications of proper names should be resolved in one operation.

The proper names which use the uncommon words, should be changed gradually with the adjustment of administrative divisions.

For proper names of administrative divisions below the county level, the one that has no distinguishing features, such as Chengguan, chengxiangzhen etc., should be get rid of in the short term.

Proper names of administrative divisions at county level should not be duplicated.

For administrative divisions which have changes on administrative level and no changes in the area of jurisdiction, generally only generic names will be changed.

\subsection{Generic Names}

In the process of county upgrades into city, we can use the scheme to change generic names and keep proper names unchanged.

\section{CONCLUSIONS}

Reform of administrative divisions mainly refers to reform of generic names. Reform of generic names of administrative divisions can take two steps. First step, complying with existing laws, cancel the name Linqu, Qi, Autonomous Qi, Meng and 
Sumu, and change it into city, county, autonomous county and Township accordingly. Generic naming system for the administrative divisions is: provincial level (province, autonomous regions and municipalities), local level (regions, autonomous prefectures and prefecture-level city), county level (counties, autonomous counties, county-level cities and municipal districts), township (township, nationality village, town, street), and it can be divided into three subsystems: (a) ordinary generic naming system: province, district, county, township; (b) generic naming system of minority autonomous region: autonomous regions, autonomous prefectures, autonomous counties, minority townships; (c) generic naming system in urban areas: municipalities, prefecture-level cities, county-level cities and city districts, towns and streets. The second step, thoroughly rationalize generic naming system of administrative divisions. The generic naming system of China's administrative divisions can be simplified as: provincial level (province, autonomous province, municipality), county level (counties, autonomous counties, cities and municipal districts), and township level (township, town, street). Three subsystems can be accordingly changed to: (a) province, county and township; (b) autonomous province, autonomous county, minority township; (c) municipalities, cities and municipal districts, towns and streets.

\section{REFERENCES}

2005. Xunzi. Jilin People’s Publishing House, Changchun.

1990. Daodejing. Anhui People’s Publishing House, Hefei.

1989. Zhuangzi. Shanghai Guji Press. Shanghai.

SHI Shu, ZHAN Dehua, 2002. Naming concept of Western and China and naming concept in Russian. Journal of Guangdong University of Foreign Studies, (3).

BA Yisi, 2010. Languages of Mo-tse. Chinese Knowledge, (1). 